\title{
A Batch Blending System for Continuous Production of Multi-Component Fuel Blends for Engine Laboratory Tests
}

\author{
Larsson, Terra; Erlandsson, Anders
}

Published in:

S A E Technical Papers

Link to article, DOI:

$10.4271 / 2020-01-2153$

Publication date:

2020

Document Version

Publisher's PDF, also known as Version of record

Link back to DTU Orbit

Citation (APA):

Larsson, T., \& Erlandsson, A. (2020). A Batch Blending System for Continuous Production of Multi-Component Fuel Blends for Engine Laboratory Tests. S A E Technical Papers, [2020-01-2153]. https://doi.org/10.4271/2020$01-2153$

\section{General rights}

Copyright and moral rights for the publications made accessible in the public portal are retained by the authors and/or other copyright owners and it is a condition of accessing publications that users recognise and abide by the legal requirements associated with these rights.

- Users may download and print one copy of any publication from the public portal for the purpose of private study or research.

- You may not further distribute the material or use it for any profit-making activity or commercial gain

- You may freely distribute the URL identifying the publication in the public portal 


\section{A Batch Blending System for Continuous Production of Multi-Component Fuel Blends for Engine Laboratory Tests}

Tara Larsson KTH Royal Institute of Technology

Anders Erlandsson KTH Royal Institute of Tech. / DTU

Citation: Larsson, T. and Erlandsson, A., "A Batch Blending System for Continuous Production of Multi-Component Fuel Blends for Engine Laboratory Tests," SAE Technical Paper 2020-01-2153, 2020, doi:10.4271/2020-01-2153.

\section{Abstract}

T he increased rates of research on complex fuel blends in engine applications poses a need for more efficient and accurate fuel blending processes in engine laboratories. Making the fuel blending process automatic, effective, accurate and flexible saves time, storage space and cost without compromising the tests of future fuel alternatives. To meet these requirements, an automatic fuel blending system, following a sequential batch process, was designed and tested for engine laboratory application.

The fuel blending system was evaluated in terms of functionality, safety, accuracy and repeatability. The functionality and safety was evaluated through a risk analysis. Whereas, the accuracy and repeatability of the system was investigated through blend preparation tests. The results show that the minimum fuel mass limitation of the system is $0.5 \mathrm{~kg}$. This allows for blends with fuel ratios as low as 7 vol- $\%$ to be prepared by the system. The mean relative errors for all tested fuels are below $5 \%$ by mass, enabling a wide range of fuels to be used in the system. The absolute error in fuel ratio is 0.5 vol- $\%$ or less. In addition, the relative error in fuel ratio of the prepared blends is below $4 \%$ for all but one of the tested blends. Moreover, the system can prepare all of the tested fuel blends in 5 minutes.

\section{Introduction}

T he interest in using renewable fuels for on-road transportation has increased due to the effect fossil fuels have on the environment, as well as concerns about future petroleum supplies $[1, \underline{2}, \underline{3}, \underline{4}, \underline{5}]$. As a result biofuels, such as ethanol and fatty acid methyl ester (FAME), are blended into the fossil fuel blend stock in many countries, either by legal enforcement or through subsidies [ $[\underline{3}, \underline{6}]$. Another result is the introduction of new biofuel-based alternatives such as E85 and ED95 in the global fuel market.

Following the introduction of renewable fuel alternatives in the fuel market, research has expanded to include investigations on additional fuel alternatives and fuel blends $[\underline{2}, \underline{5}, \underline{7}, \underline{8}$, 9]. The increased variation in fuel compounds and blends in engine research has resulted in the need for multiple fuel blends to be prepared accurately and effectively. Today the most common procedure is to manually splash blend the amount of fuel needed. In splash blending the fuel components are added into a container and mixed moderately (if mixed at all) $[\underline{6}, \underline{9}, \underline{10}]$.

The splash blend approach is well suited for the occasional preparation of fuel blends. However, it requires certain resources to ensure safe handling and storage of the fuels. This includes adequate space with appropriate ventilation, containers for preparation of the mixtures and enough storage capacity to store the individual fuel components as well as the fuel blends. Hence, the splash blend approach can become inefficient in terms of time and space. Moreover, the method introduces uncertainties in the fuel ratios, the homogeneity and the quality of the fuel blends, especially if stored over a long time [11]. A nationwide study in the USA showed that in the case of biodiesel/petroleum diesel blends the measured volumetric content for the fuels where incorrect in $36 \%$ of the tested cases [6].

This article describes the development and evaluation of a batch blending developed to facilitate testing of multiple liquid fuel blends, to ensure accuracy, repeatability and homogeneity and to decrease the time and space needed for mixture preparation. This paper presents the chosen hardware and software design, as well as results on the functionality, accuracy and repeatability of the system.

\section{Blending Liquids (Theory)}

Mixing or blending is necessary in many chemical processes to ensure homogeneity [12]. For fuel blends, this is of course

(c) 2020 Tara Larsson, Anders Christiansen Erlandsson. Published by SAE International. This Open Access article is published under the terms of the Creative Commons Attribution License (http://creativecommons.org/licenses/by/4.0/), which permits distribution, and reproduction in any medium, provided that the original author(s) and the source are credited. 
important to ensure steady performance of the engine, especially for research purposes. The mass of each fuel component can be determined either gravimetrically or by using mass flow controllers (MFCs). One option is Coriolis mass flow meters, which are commonly used in industries due to their high accuracy $[\underline{13}, \underline{14}]$. However, the accuracy of these MFCs can be affected by vibrations within a specific frequency range $[13, \underline{14}]$. Sources of such vibrations could be pumps, motors or air-conditioning [14]. In this application, the MFCs for the batch blending system would have to be within an environment where several of those sources are present hence, did not seem like a suitable option for this application.

Another option of MFCs are thermal MFCs, which have shown to be a good choice for the mixing of gaseous fuels $[15$, 16]. However, as the thermal MFCs could only be used with limited differential pressures they may not work within an application where the flow is not constant [17], such as the case for blending multiple liquid fuels. Therefore, the third approach using a gravimetric method to measure differential fuel masses seemed more fitting with regard to this specific application. Neither the vibrations from surrounding equipment nor the variations in fuel flow would heavily affect the scale response, and it was also considered the cheapest option of the three. Moreover, a gravimetric approach for fuel blending has exhibited high accuracy when used in other studies [10].

Once the fuel is added, it has to be mixed to ensure homogeneity. Mixers or vessels where non-reactive and reactive processes occur can be separated into three main reactor types: continuously stirred tank reactors (CSTR), tubular flow reactors and batch reactors $[\underline{18}, \underline{19}, \underline{20}]$. In this article, only batch reactors are discussed since the batch blending system is built based on a sequential batch blending process.

The applied process is similar to that used in the chemical industry and oil refineries [21, 22, 23]. A batch blending approach offers advantages in flexibility of fuel formulation and allows all fuel components to be added and properly mixed before the fuel is introduced to the engine $[\underline{18}, \underline{22}, \underline{23}, \underline{24}, \underline{25}]$. However, the main drawback is the time-dependence of the chosen process as every step of a batch process has to occur for a set amount of time before the products can be retrieved [25].

\section{Fuel Blending System Design}

The design target is an easily adaptable system that can be used either on its own or in direct connection with engine testing. The system design should be able to be applied to different engine types and sizes. However, this specific system was developed for a light-duty (LD) spark ignited (SI) engine and for engine laboratory purposes only. For vehicle application, specific constraints other than the ones evaluated in this article need to be considered.

The batch blending system also needs to be able to perform with a high enough accuracy independent of the fuels used in the blend. The properties that could affect the fuel flow, and hence the accuracy of the system, are density and viscosity which may vary a lot between different fuels (see Table 1). Therefore, the system needed to comply with these variations.
TABLE 1 Fuel properties for the four different fuels at $20^{\circ} \mathrm{C}$. Density for gasoline and ethanol was measured.

\begin{tabular}{|l|l|l|l|l|}
\hline Fuel & Gasoline & Ethanol & Methanol & Iso-butanol \\
\hline Density (kg/m3) & 728 & 796 & $798[\underline{26}]$ & $801[\underline{26}]$ \\
\hline Viscosity (mPa.s) & $0.4[2]$ & $1.5[\underline{2}]$ & $0.6[\underline{26}]$ & $8.3[\underline{2}]$ \\
\hline & \multicolumn{4}{c}{ ○ Tara Larsson, Anders Christiansen Erlandsson. }
\end{tabular}

TABLE 2 The system requirements for the fuel batch blending system.

\begin{tabular}{l|l|}
\hline Hardware requirements: \\
\hline 1. & Handle corrosive fuels \\
2. & EX-class electrical equipment \\
3. & Possibility to change parts \\
\hline 4. & Alarms in case of fire, leakage or blending issues \\
\hline 5. & Scale precision of 1 gram \\
\hline \multicolumn{1}{|c|}{ Software requirements: } \\
\hline 1. & Automatic fuel preparation \\
\hline 2. & Continuous monitoring of the batch blending process \\
\hline 3. & Possibility to log system data \\
\hline 4. & User notifications in case of fire, leakage or blending issues \\
\hline Functional requirements: \\
\hline 1. & Mixing fuels while simultaneously running engine tests \\
\hline 2. & Relative errors in fuel mass $\leq 5 \%$ \\
\hline 3. & Ability to mix different fuels (concentrations and \\
\hline 4. & Remponents) \\
\hline 5. & Concentration consistent throughout prepared blends \\
\hline 6. & Blend preparation time of less than 5 minutes \\
\hline 7. & Minimal manual handling of fuel \\
\hline 8. & User safety \\
\hline
\end{tabular}

\section{System Requirements}

The requirements set for the system to fulfill the design target are divided into three categories: hardware requirements, software requirements and functional requirements (including safety requirements). All of the system requirements are listed in Table 2. Since this specific system was developed for a LD SI engine, other requirements might be needed for heavy-duty (HD) applications.

\section{Hardware Design}

A schematic drawing of the overall hardware design of the batch blending system is presented in Figure 1. The proposed design is based on feedback of added fuel mass from a scale. This approach was chosen as the scale response is generally not disturbed by vibrations, unlike MFCs. The system contains three fuel inlets; however, it can be adapted to contain more inlets if desired. Inlet 1 and 2 can be directly connected to the existing fuel storage and utilize the already existing pumps of the test cell to pump fuel to the system. Whereas, inlet 3 can be connected to a specific fuel container inside the test cell for the addition of specific fuels to the blend; hence inlet 3 is connected with its own separate pump. 
FIGURE 1 Sketch of the hardware setup for the fuel blending system, where 1-3 are the system inlets, 5-7 are solenoid valves, 8 and 14 are fuel pumps, 9 is a pneumatic motor, 10 is the mixing vessel, 11 is the agitator, 12 is the scale, 15 is a pressure regulator, 16 is the fuel return line, 17 is the system outlet, 18 and 20 are pressure sensors, 4,13 and 19 are thermocouples, 21 is a liquid level switch and 22 is the buffer tank.

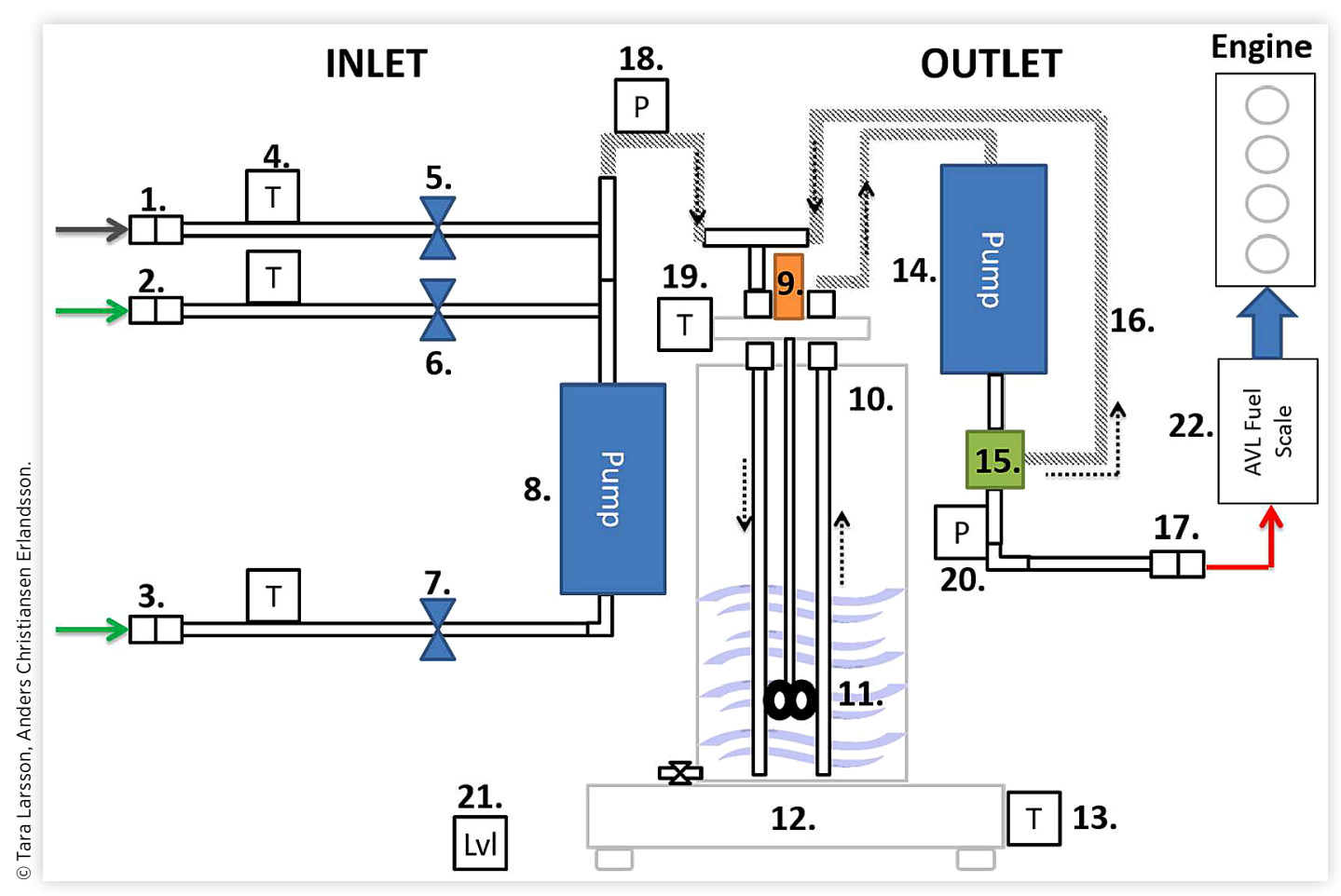

The fuels are added automatically, using pumps and valves, to a mixing vessel, in this case a cylindrical container in stainless steel. A rotary blade agitator is located in the container, which mixes the components in both vertical and axial planes [19].

A buffer tank is placed between the mixing system and the engine to ensure that the fuel blend is available at the engine fuel pump inlet at all times. In this case, (LD engine) the buffer tank consists of a 21 AVL fuel scale (see 22. in Figure 1). In the case of HD applications, there is a need for a larger buffer tank, since the fuel consumption will be significantly higher.

All of the materials in the system are compatible with Class 1 fuels as well as resistant to aggressive fuels such as methanol, dimethyl ether (DME) and oxymethylene dimethyl ethers (OME) [27, 28, 29]. Hence, the material of the system consist of mainly stainless steel piping and PTFE hoses with stainless steel covering. The solenoid valves, pressure sensors and pneumatic motor for the stirrer (5-7, 18, 20 and 9 respectively in Figure 1) are all EX-classed. A spill plate is located underneath the system connected with a liquid level switch alarm in case of fuel leakage.

The container is custom-built with a diameter of $250 \mathrm{~mm}$ and a height of $350 \mathrm{~mm}$. A tap is located at the side to empty the container or to retrieve fuel samples. The lid above the container prevents flammable gases leaking into the surrounding air. The lid rests on a stand above the container, not on the container itself, to avoid interference of changes in fuel flows on the scale output. The scale is a load cell scale
(OHAUS Ranger 7000) with a max capacity of $35 \mathrm{~kg}$ and a precision of $0.5 \mathrm{~g}$. A mass value is retrieved by the system software every $100 \mathrm{~ms}$. Detailed information on all hardware is presented in Appendix 1.

\section{Software Design}

The software requirements for the batch blending system are: automatic fuel preparation, potential to log system data, ability to monitor the blending process and alarms in case of fire, leakage or blending issues. Therefore, a system software was developed for automatic fuel preparation with a graphical user interface (GUI) to facilitate the overview of the fuel blend preparation process. The system control and the GUI were developed in National Instruments (NI) LabVIEW. The I/O-signals connected to the system hardware are processed using a CompactRIO (cRIO) and related modules from NI.

Control Strategy The system is controlled in LabVIEW using a so-called "Moore machine", which is a form of finite state machine (FSM), where the output only depends on the current state [30] rather than all previous operations as is typical for an FSM [31].

The batch blending system is controlled through 5 states (see Figure 2). The default state is 'Initiation', thus the control system returns to this state whenever the fuel has been consumed or the system is restarted. At start-up, the system 
FIGURE 2 Schematic of the batch blending system control algorithm.

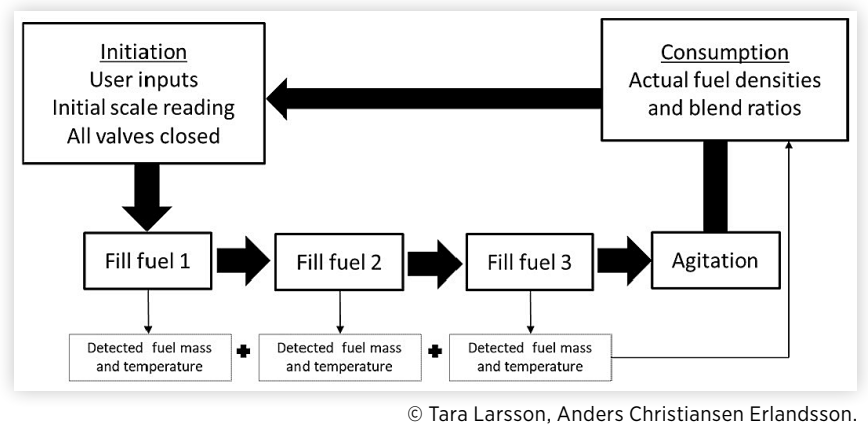

waits for the user command to start the fuel preparation process before it enters the initiation state. During this state the initial condition of the system is confirmed (temperatures, user inputs, mass etc.). The following states ('Fill fuel 1', 'Fill fuel 2' and 'Fill fuel 3') handle the addition of the different fuel components.

The software always fills the fuels in this order. However, if any of the fuels are disabled, the state will continue directly to the next fuel. The fuel mass of each fuel component is calculated by the system using the fuel ratio input (vol-\%) and the fuel densities at the reference temperature $\left(20^{\circ} \mathrm{C}\right)$. The inlet valve is opened (inlet 1 for 'Fill fuel 1' etc.) and kept open until the signal from the scale reaches the value of the calculated fuel mass. Subsequently the valve is closed and the system detects the actual fuel mass and fuel temperature before going into the next state.

After all the fuels have been added the system calculates the fuel ratios based on feedback signals from the scale and thermocouples in the fuel inlets. These values are displayed to the user (and logged) immediately after the blend preparation has been completed. Thereafter the system goes into the state 'Agitation'. In this state, the fuels are mixed to prevent inhomogeneity throughout the batch. The last state is 'Consumption'. The outlet pump of the system transports the fuel blend to the buffer tank and on to the engine. The 'Consumption' is stopped when the mass of the fuel is equal to or below the set minimum level of the mixing vessel. Consequently, the system returns to the default state ('Initiation').

Graphical User Interface A graphical user interface (GUI) was developed to give the operator an accessible overview of the system and the process (see Figure 3 ). In the GUI the user can specify how many fuels (1-3 fuels in this set-up) should be mixed and what fuels and fuel ratios the blend should consist of. The valves and pumps that are active are shown using LED indicators.

The amount of fuel in the mixing vessel is displayed both in volume (l) and in mass (kg). The user can follow the fuel flow continuously (using the chart) and log the data using the "Save data" button. Moreover, if needed, the user can change the volume of the prepared blend.

Alarms for vessel overflow, fuel leakage, faulty fuel mix settings and log-file problems are all added in the program.
The program gives a warning message and is stopped by the user in case of any of these events.

\section{System Evaluation Method}

The functionality of the fuel batch blending system was evaluated based on how well the system met the requirements set in Table 2.The evaluation focuses on three areas: the measurement accuracy of the scale, the system related errors and limitations, and the preparation of fuel blends (including risk analysis). For every test a 95\% confidence interval was calculated using t-student distribution to ensure the statistical validity of the reported results. If not otherwise mentioned, the tests were repeated 5 times and gasoline was used as the tested fuel.

\section{Evaluation of Measurement Accuracy}

The measurement accuracy of the fuel batch blending system relies on the accuracy of the response of the feedback signals. For the control of the batch blending system, the most important feedback signal is the mass signal from the scale. Therefore, it is important to establish the highest measurement accuracy possible for this signal while filling, and to implement signal-processing strategies to optimize this accuracy.

Influence of Mass Averaging on Measurement Accuracy The signal response from the scale is rapid and precise enough to detect small changes in added fuel mass, which is important for accurate control of the system. However, it also results in intermittent peaks in the signal when the fuel flows into the mixing vessel. This could cause random errors in the mass signal, which affects the system control. The chosen approach to minimize the signal noise is to apply a moving average to the scale signal (see Figure 4).

The signal was evaluated using a moving average with a window of 1 to 10 data points (moving average using 1,2, 5, 8 and 10 data points were tested). The valve was closed when the averaged mass measurement reached the value of the demanded mass (see Table 3). Thereafter, the actual mass added was compared to the demanded mass. All the tests were performed using inlet 3 .

\section{System Related Errors and Limitations}

Random errors, systematic errors and system limitations for the batch blending system were detected and quantified.

Random Errors The identified random errors of the batch blending system are the variation in fuel flow, inlet pressure, 
FIGURE 3 The graphical user interface (GUI) of the system software.

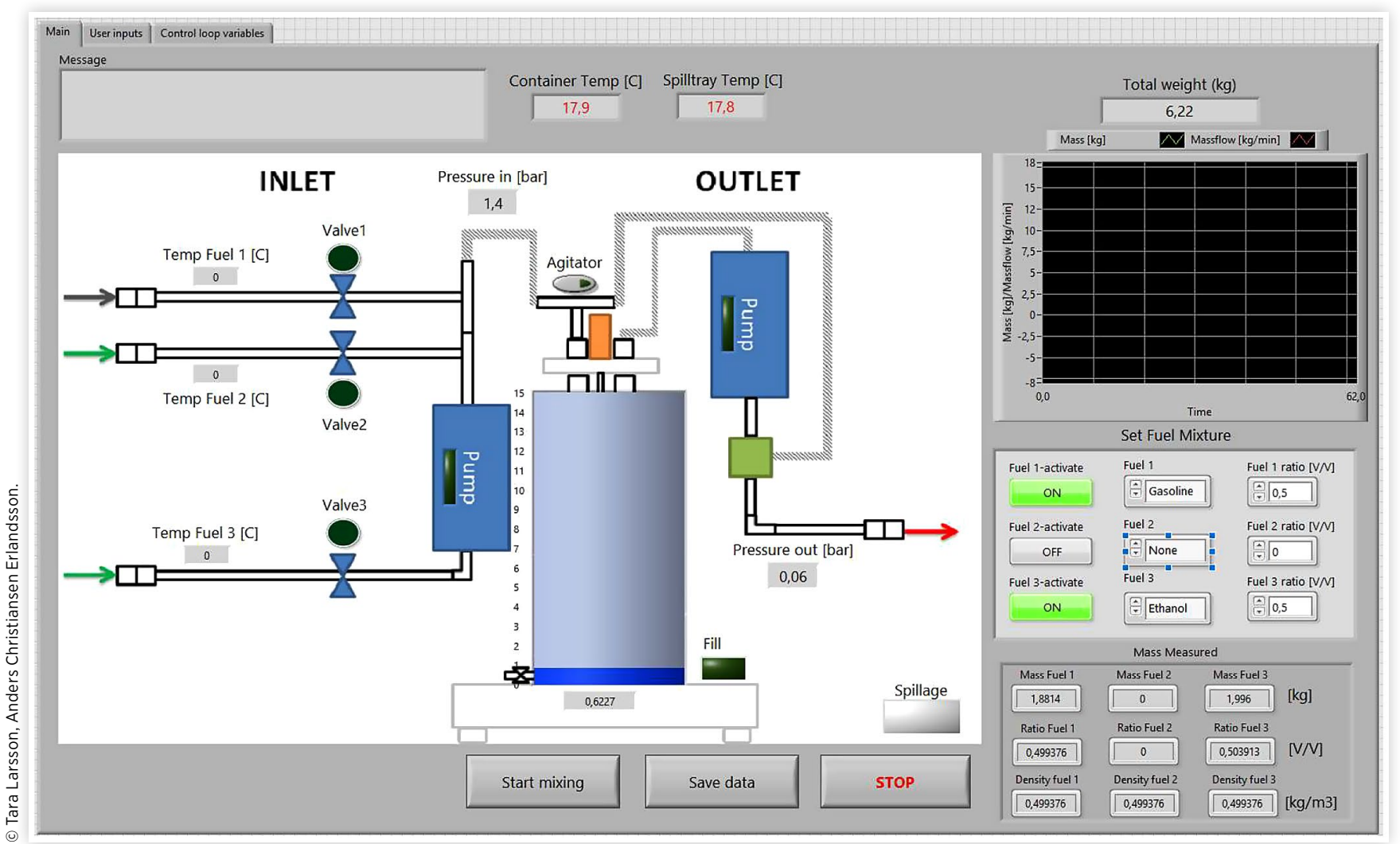

FIGURE 4 Example of mass signal without and with moving average implemented.

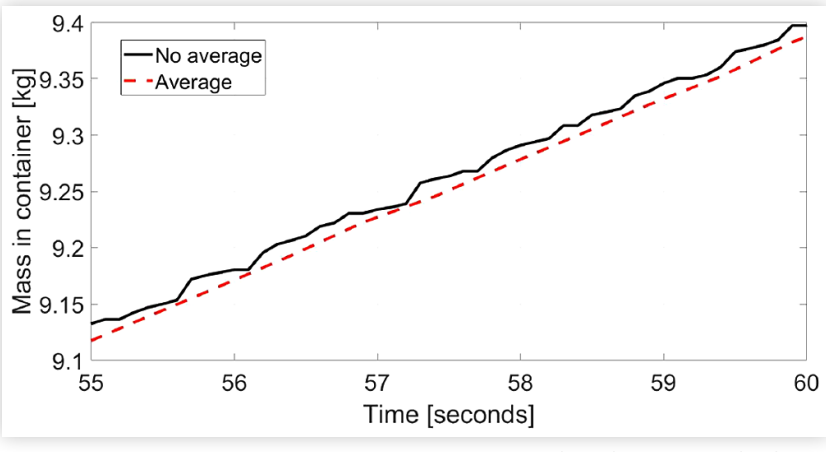

outlet pressure and temperature (both fuel temperature and test cell temperature). All of these variations affect he flow rate of fuel mass into the mixing vessel, hence affecting the accuracy of the implemented control logic. The random errors cannot be accounted for in the control of the batch blending system. Therefore, they are quantified to ensure that they do not significantly affect overall system accuracy.

Temperature, pressure and fuel flow were monitored during all tests to detect mean values and variations. Temperatures were measured with thermocouples located on each fuel inlet, above the fuel container and above the spill plate. Pressures were measured using pressure sensors. The inlet pressure sensor is located after the junction of all fuel
TABLE 3 The tested mass values for test on the influence of mass averaging on measurement accuracy and for quantifying random errors.

\begin{tabular}{|c|c|}
\hline Relative mass & Actual mass (kg) \\
\hline Minimum mass & 0.5 \\
\hline Minimum mass*1.1 & 0.55 \\
\hline Minimum mass*1.2 & 0.6 \\
\hline Minimum mass*1.5 & 0.75 \\
\hline Maximum mass*0.25 & 1.8 \\
\hline Maximum mass *0.5 & 3.65 \\
\hline Maximum mass $* 0.75$ & 5.5 \\
\hline Maximum mass *0.9 & 6.6 \\
\hline Maximum mass ${ }^{*} 0.95$ & 7.0 \\
\hline Maximum mass & 7.3 \\
\hline
\end{tabular}

inlets and the outlet pressure sensor is located on the outlet after the return line (see Figure 1). The fuel flow was calculated from the mass signal retrieved from the OHAUS load cell scale.

Systematic Errors The main systematic error of the fuel batch blending system was identified as the inertia of the system in regards to the inlet valves and pump, especially during valve closing. The control of the valves and pumps in the system is dependent on accurate detection of when the fuel mass is equal to the calculated desired fuel mass. When this occurs the software sends a signal to the system to close 
FIGURE 5 Fuel mass flow and valve activation/deactivation over time. The marked sections in the graph are the offsets for the valve activation and the valve deactivation.

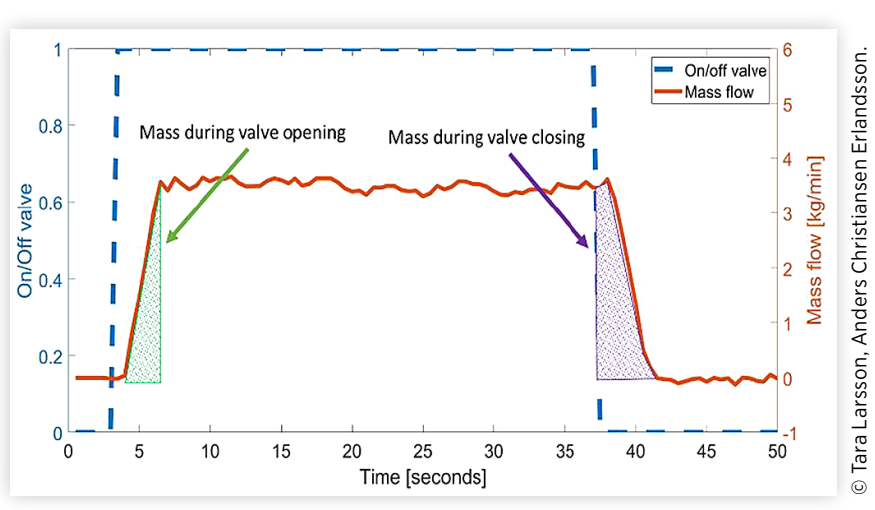

the valve. However, due to inertia in the system the valve is not fully closed immediately after this signal has been sent. The time between sending out the signal to close the valve and the valve being fully closed is defined as the valve deactivation (and valve activation for the event of opening the valve). These events are displayed in Figure 5.

During valve activation less fuel is added as the valve is not fully opened. During valve deactivation additional fuel is added to the mixing vessel as the valve is not yet fully closed. This causes a systematic error, which affects the accuracy of the actual added fuel mass. The fuel mass added during valve activation or valve deactivation is defined as valve offsets. As this is a systematic error, it can be accounted for in the system control if quantified.

The systematic errors were quantified by measuring the change in fuel mass in the mixing vessel during valve activation and deactivation 10 times for each inlet. Mean values for the detected valve offsets were calculated for activation and deactivation for each inlet.

\section{System Limitations}

Evaluation of Linearity and Accuracy of System Inlets The main limitation of the system is the minimum fuel mass that can be added while still obtaining the requested accuracy (see Table 2). This limitation can be said to depend on two factors. The first is the limit of minimum fuel mass that can be added to the mixing vessel. This is the mass value at which the system deviates from the linearity between added fuel mass and demanded fuel mass. The second factor is the limit at which the accuracy of the added mass is lower than required. These limits could occur at the same mass value, but it is not certain and thus they were evaluated separately.

The system linearity and the accuracy limit of each inlet were determined by comparing the actual mass added in the mixing vessel to the demanded mass. The tests were conducted for each inlet and for 9 different masses close to what is assumed to be the minimum mass that can be added to the mixing vessel with good enough accuracy: 0.05, 0.1, 0.12, 0.15, $0.2,0.5,0.75,1.0$ and $2.0 \mathrm{~kg}$ (the maximum weight for gasoline would be approximately $7.3-7.5 \mathrm{~kg}$ ).
TABLE 4 Demanded masses during fuel property tests.

\begin{tabular}{|l|l|}
\hline Relative mass & Actual mass $(\mathbf{k g})$ \\
\hline Minimum mass & 0.5 \\
\hline Minimum mass*1.2 & 0.6 \\
\hline Minimum mass*1.5 & 0.75 \\
\hline Maximum mass*0.25 & 1.8 \\
\hline Maximum mass ${ }^{*} 0.5$ & 3.65 \\
\hline Maximum mass & 7.3 \\
\hline & ๑ Tara Larsson, Anders Christiansen Erlandsson.
\end{tabular}

\section{Effect of Variation in Fuel Properties on System} Accuracy Another limitation of the system control is the capability of the system to comply with different fuels and fuel properties without a significant effect on the accuracy of the control system.

The effect of fuel properties on the accuracy of the added mass was evaluated. The demanded fuel masses were varied according to the values in Table 4 . The tested fuels were gasoline, ethanol, methanol and iso-butanol. The viscosity and density of the tested fuels are shown in Table 1. All the tests were performed using inlet 3 .

\section{Evaluation of Fuel Blend Preparation}

The requirements for fuel blend preparation (see Table 2) are a maximum relative error in fuel ratio of $5 \%$, homogeneity throughout the prepared fuel blend, and that fuel preparation takes no longer than 5 minutes. Moreover, the fuel batch blending system should offer fuel blend preparation with minimal manual handling and increased safety. The evaluation of the blend preparation of the fuel batch blending system is based on how well the system meets these requirements.

Accuracy in Concentration between Blends The batch blending system calculates the fuel mass that should be added for each component based on a set reference temperature $\left(20^{\circ} \mathrm{C}\right)$. Assuming there are variations in the fuel temperatures between $-5^{\circ} \mathrm{C}$ and $60^{\circ} \mathrm{C}$ (affecting the fuel density), this could impose an error of maximum $3 \%$ relative to the expected fuel ratios of the demanded fuel blend.

The accuracy and the variation in ethanol concentrations between prepared blends were tested. These parameters were evaluated for four different fuel blends of ethanol and gasoline at room temperature $\left(16-20^{\circ} \mathrm{C}\right)$. The tested blends were $\mathrm{E} 5$, E20, E50 and E95 (the number indicates the ethanol ratio of the blend in vol-\%). The volume of each of the prepared blends was 10 liters. Gasoline was added using inlet 1 and ethanol was added through inlet 3 .

The ethanol ratio was evaluated by gravimetric analysis of the fuel density compared to a linear interpolation of pure ethanol and pure gasoline $\left(786 \mathrm{~kg} / \mathrm{m}^{3}\right.$ and $730 \mathrm{~kg} / \mathrm{m}^{3} \mathrm{respec}-$ tively). Moreover, the estimated ethanol ratio from the gravimetric analysis was compared to the expected ratio. 
Variation in Concentration within a Batch The homogeneity in the fuel ratio of the blends was tested for four different concentrations (E5, E20, E50 and E95) to establish the agitation time needed, defined as the necessary time for agitation to ensure homogeneity throughout the mixing vessel. The samples were retrieved by pipette from the mixing vessel at different times (0, 30, 60 and 90 seconds) and spatial locations (2, 6 and $10 \mathrm{~cm}$ from the mixing vessel bottom). The concentrations were evaluated by gravimetric analysis for each sample.

Fuel blends containing ethanol and gasoline was chosen since ethanol has low miscibility in gasoline [32] and due to the limitations of fuels available for testing.

Fuel Blend Preparation Time One of the requirements listed in Table 2 is the time it takes to prepare one fuel mixture using the batch blending system. The preparation time needs to be lower than the time it takes to empty the buffer tank. Therefore, the maximum fuel blend preparation time was investigated.

The fuel blend preparation time was defined as the maximum time to fill 10 liters of a fuel mixture plus the agitation time. The time to fill a fuel from each inlet was estimated using the mean fuel mass flow of each inlet with gasoline as fuel. Since the computational time of the system is lower than 1 second, this time was considered to be negligible.

Risk Analysis To ensure minimal manual handling and safe usage of the system a risk analysis was performed for the chosen batch blending system design using U.S. National Fire Protection Association (NFPA) classification for different fuels in combination with Hazards and Operability studies

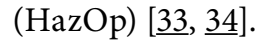

\section{Results and Discussion}

The result section will present and discuss results mostly related to the accuracy of the fuel mixing system. However, in the risk analysis some areas related to the system functionality and safety will be briefly evaluated.

\section{Evaluation of Measurement Accuracy}

For the measurement accuracy to be optimized the effect of a number of samples for mass averaging on the system response was investigated according to Table 3 .

Influence of Mass Averaging on Measurement Accuracy The effect of the moving average on the mass signal can be seen in Figure 6. The inertia of the detected mass average increases if more data points are used for the moving average. Therefore, the moving average using 8 or 10 data points gives a delayed response to close the valves. The delay could be adjusted for using a mean value for the time as well; however, as the control of the system is dependent on real-time

\section{FIGURE 6 Magnified mass signal during a fuel fill event.}

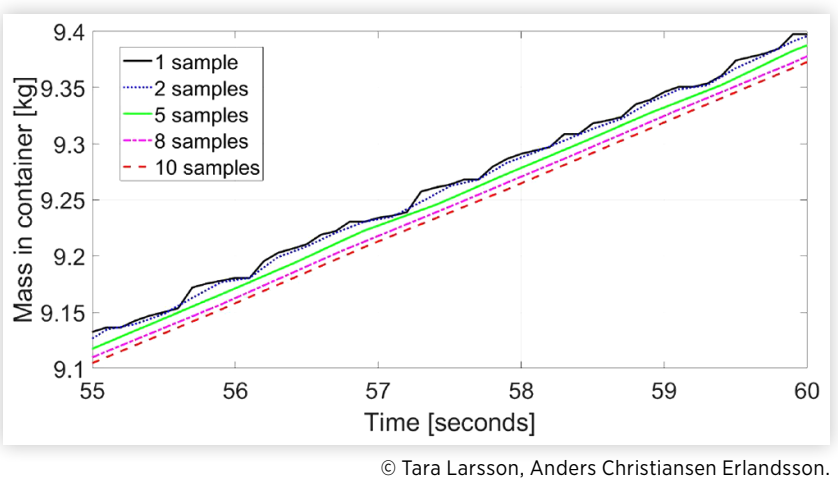

data it is not possible in this case. The result instead becomes a constant underestimation of the actual mass value.

If only one data point is used the oscillations of the signal response are still detected by the system (see Figure 6). The peaks in the signal lead to increased uncertainty of the true mass value. This may cause a premature detection of the threshold value which closes the valve before the demanded fuel mass has been obtained. For a moving average using 5 data points the local peaks are filtered out from the signal, decreasing uncertainty, but without an underestimation of the true signal due to inertia.

The absolute error for the different numbers of data points used for the moving average can be seen in Figure 7. The absolute error is approximately constant for all averages over the tested fuel mass range $( \pm 5-30 \mathrm{~g})$. Hence, there is no effect on the absolute error from the fuel mass. The case with the highest error in accuracy (Figure 7) is for a moving average of 10 data points.

The results in Figure 7 agree with the findings in Figure 6. The absolute errors for 1 or 2 data points show negative error values consistent with a premature valve closing. Whereas 8 or 10 data points show positive error values, consistent with an underestimation of the mass signal. The lowest absolute error was seen for a moving average of 5 data points. The same case also exhibited the lowest standard deviation, which indicates that a moving average can be used to increase the measurement accuracy of the feedback signal. From the performed test it is concluded that implementing a moving average of 5 data points would yield the highest accuracy for this system.

\section{System Related Errors and Limitations}

The random and systematic errors, the system limitations and the system response to different fuels were examined to find the optimal control settings for the batch blending system.

Random Errors The mean values and absolute variations of the pressures and fuel flow in the batch blending system can be seen in Table 5. The variation for pressure was 0.01 bar and for fuel flow $0.1-0.4 \mathrm{~kg} / \mathrm{min}$. These values were considered to be low and not have a significant effect on the accuracy of the system control. However, as the presented results are only 
FIGURE 7 Absolute error with standard deviation for different number of samples for average.

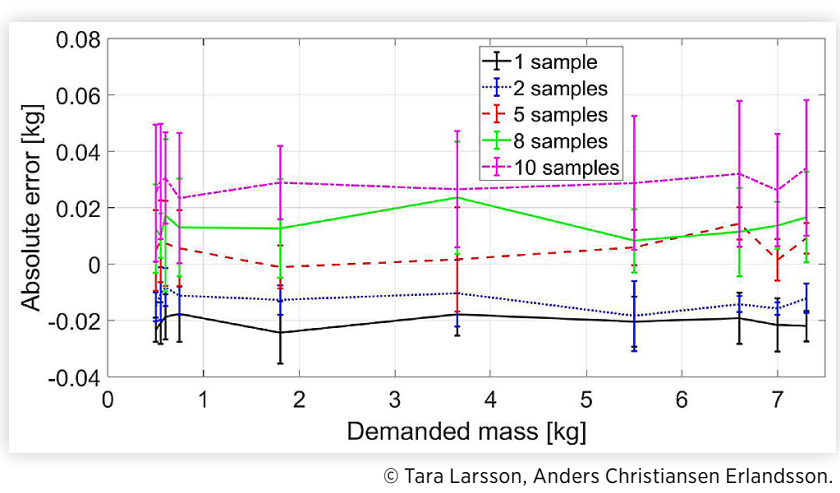

TABLE 5 The measured mean values and absolute variations for pressure and fuel flow in the batch blending system.

\begin{tabular}{l|l|l|l|l|} 
& \multicolumn{2}{l}{ Pressure (bar) } & \multicolumn{2}{l|}{ Fuel flow $(\mathrm{kg} / \mathrm{min})$} \\
\cline { 2 - 5 } Inlet & Mean & Variation & Mean & Variation \\
\hline 1 & 2.36 & 0.01 & 5.2 & 0.4 \\
\hline 2 & 2.36 & 0.01 & 5.3 & 0.4 \\
\hline 3 & 2.36 & 0.01 & 3.1 & 0.1 \\
\hline Outlet & 1.1 & 0.01 & 3.5 & 0.1 \\
\hline \multicolumn{5}{r}{ ○ Tara Larsson, Anders Christiansen Erlandsson. }
\end{tabular}

TABLE 6 The mean values, variation interval (95\% confidence interval) and the repeatability (percentage of samples within the confidence interval) for valve activation (A) and valve deactivation (D) for all system inlets.

\begin{tabular}{llll|l|l|l|} 
& \multicolumn{2}{c}{ Mean [kg] } & \multicolumn{2}{c|}{ Variation [kg] } & \multicolumn{2}{c|}{ Repeatability [\%] } \\
\cline { 2 - 7 } Inlet & A & D & A & D & A & D \\
\hline 1 & 0.29 & 0.12 & 0.04 & 0.03 & 70 & 80 \\
\hline 2 & 0.28 & 0.11 & 0.04 & 0.03 & 70 & 90 \\
3 & 0.38 & 0.08 & 0.14 & 0.01 & 60 & 80 \\
\hline
\end{tabular}

based on gasoline it could be expected that the variation in fuel flow with regard to different fuels exhibit higher variation.

The temperature variation within the engine test cell is within $10^{\circ} \mathrm{C}$ and the variation in fuel temperature is between 9 and $18^{\circ} \mathrm{C}$. The fuel density is not significantly affected by temperature variations detected during tests [35, $\underline{36}]$. Therefore, no significant effect on system accuracy due to the temperature variations is expected.

Quantification of Systematic Errors (Mass Offset) The mean values for the mass offset for valve activation (open) and valve deactivation (close) for each inlet can be seen in Table 6 . As the changes in fuel flow were relatively low it was surprising that the repeatability for valve activation was only $60-70 \%$. The low range of the confidence interval might explain this. The ranges are small compared to the flow variations detected (see results on 'Random errors'). The confidence interval for valve deactivation was smaller than for valve activation, and the repeatability was higher (80-90\%).

Since the system only controls the valve deactivation based on the mass signal the offset during valve activation is not affecting overall system accuracy. However, during valve deactivation additional fuel is added to the mixing vessel and cause a systematic error to the added fuel mass. Since the repeatability for valve deactivation was high, the results indicate that a high enough accuracy throughout system operation can be achieved, but only if adjustments of the control logic for the mass offsets at valve deactivation are implemented.

An interesting result is that inlet 3 shows the highest variation for valve activation, but the lowest for valve deactivation. This is probably due to the design of the system, where inlet 3 is equipped with an internal fuel pump, while the flows in inlet 1 and 2 are controlled with external pumps. The results suggest that the internal pump has a varying response at startup, but as the output signal is controlled via a relay this gives a more accurate response than the valves alone at deactivation. The pump outlet is also located closer to the mixing vessel than the valves; hence the effect of remaining fuel in the pipes is lower for inlet 3 than for inlet 1 and 2 .

System Limitations The system limitations are the linearity limit of the system, the accuracy at low added masses and the system response to different fuel properties. All of these were tested and evaluated.

Evaluation of Linearity of System Inlets The minimum fuel mass that can be added to the system is detected by evaluating when the system response can no longer meet the value of the demanded mass. This causes the actual mass value to deviate from the linear line between added mass and demanded mass. As can be seen in Figure 8, the system response deviated from the linearity at target masses below $0.15 \mathrm{~kg}$ for inlets 1 and 2 and below $0.1 \mathrm{~kg}$ for inlet 3 . This is due to the inertia of the system (see 'Quantification of systematic errors'). Hence, the system response is not rapid enough to ensure accuracy of demanded fuel masses below the limit of the valve response for each inlet. Inlet 3 has the lowest limit of linearity, which is consistent with the fact that inlet 3 has the lowest systematic error for valve deactivation.

FIGURE 8 Comparison of actual mass with standard deviation and demanded mass for the different system inlets.

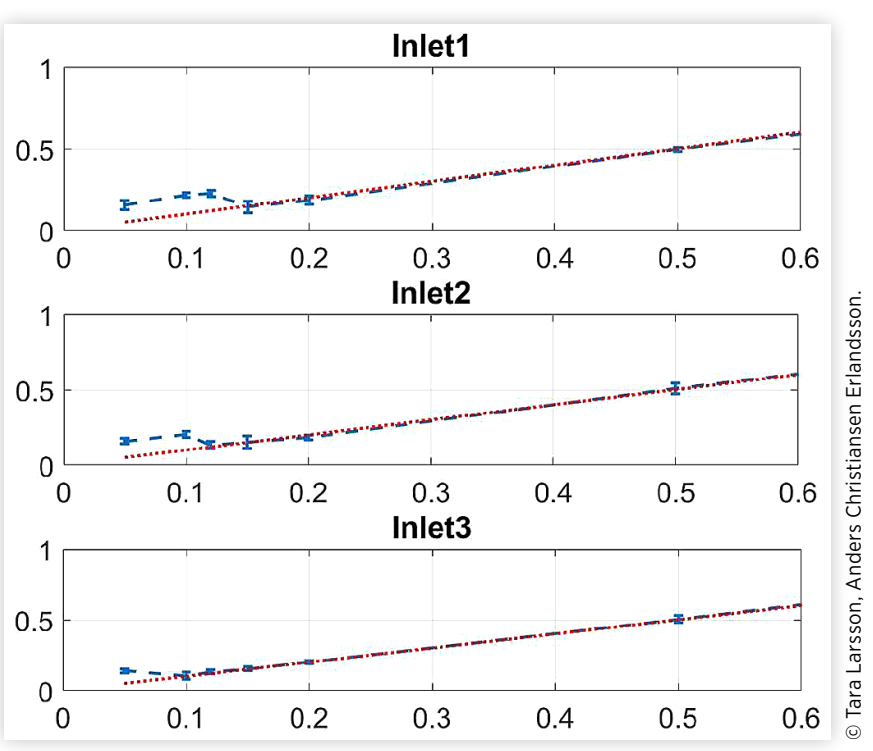


Evaluation of Accuracy of System Inlets The mass limit for the maximum relative error in mass (5\%, see Table 2 ) was investigated. This limit is a result of the linearity of the system, such as the systematic errors and the signal delay. As can be seen in Figure 9, the error is higher than the required $5 \%$ at target masses below $0.5 \mathrm{~kg}$. For this value, the mean values of all inlets are close to the required accuracy. However, the response is not repeatable for masses below $0.5 \mathrm{~kg}$, as can be seen for the increase in standard deviation at lower demanded mass.

The inlet exhibiting the highest accuracy is inlet 3, which is coherent with the stability of the flow of this inlet (see results on 'Random errors'). For inlet 1 and 2 some of the measured values show errors above $5 \%$ at $0.5 \mathrm{~kg}$. Therefore, adding the fuel with the lower fuel ratio from inlet 3 would ensure higher accuracy in the prepared fuel blend.

Effect of Variation in Fuel Properties on System Accuracy The effect of different fuels on mass accuracy and the valve response error were investigated. The results can be seen in Figure 10 and Table 7.

The absolute error for all the tested fuels is within the range of -0.02 to $0.05 \mathrm{~kg}$ and there is no correlation to the demanded mass value. Hence, the relative error decreases with the demanded mass as can be seen in Figure 10.

The mean relative errors for all the tested fuels are lower than the required 5\%. However, the standard deviation is outside the limits for methanol and ethanol for the lowest

FIGURE 9 The relative error of the added mass for different demanded mass and system inlets.

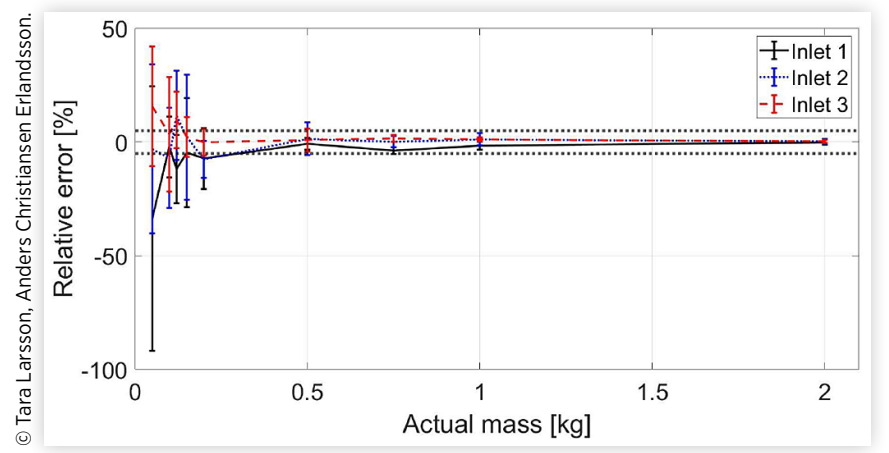

FIGURE 10 The relative error of the added mass for four different fuel components.

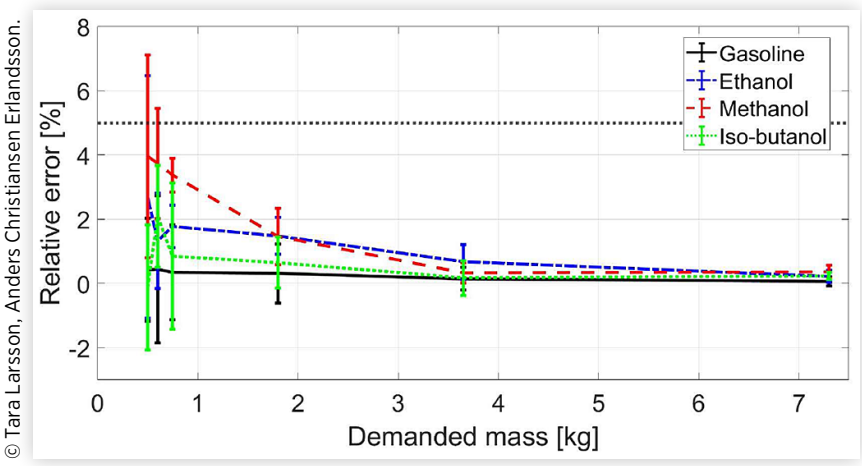

TABLE 7 The mean values, variation interval (95\% confidence interval) and the repeatability (percentage of samples within the confidence interval) for valve activation $(A)$ and valve deactivation (D) for four tested fuels.

\begin{tabular}{ll|l|l|l|l|l|}
\hline & \multicolumn{2}{l}{ Mean [kg] } & \multicolumn{2}{l|}{ Variation [kg] } & \multicolumn{2}{l|}{ Repeatability [\%] } \\
\cline { 2 - 8 } & A & D & A & D & A & D \\
\hline Gasoline & 0.18 & 0.08 & 0.04 & 0.01 & 70 & 60 \\
\hline Ethanol & 0.21 & 0.08 & 0.06 & 0.01 & 70 & 90 \\
\hline $\begin{array}{l}\text { Methanol } \\
\text { Iso- }\end{array}$ & 0.21 & 0.08 & 0.06 & 0.03 & 70 & 60 \\
butanol & 0.19 & 0.07 & 0.05 & 0.03 & 30 & 70 \\
\hline
\end{tabular}

(c) Tara Larsson, Anders Christiansen Erlandsson.

demanded mass value of $0.5 \mathrm{~kg}$. This could cause lower accuracies for blends containing those fuel components in low ratios.

The results of the effect on the valve offset of the different fuels can be seen in Table 7. It was established that the deviations due to different fuels were relatively small $(\leq 0.06 \mathrm{~kg})$ in terms of absolute values. Hence the effect on overall blend preparation accuracy is not expected to be significant. Moreover, all of the tested fuels exhibit a mean value close to the previously established $0.08 \mathrm{~kg}$ at valve deactivation (see results on 'Systematic errors'). Thus, this value can be considered a valid offset regardless of the fuel component used. However, the valve response for valve activation is much lower than the previously established $0.4 \mathrm{~kg}$. This indicates that the effect on valve response at valve activation is more sensitive to changes (demanded mass or fuel component) than the valve response at valve deactivation.

Methanol and ethanol exhibit the highest variation in the measured offset for valve deactivation (see Table 7), which causes higher insecurities in the blends prepared with these fuels. Furthermore, the lowest repeatability for valve deactivation is seen for methanol, in combination with gasoline. Therefore, methanol would be the fuel component introducing the highest uncertainty to the system control when mixed. It was found that this behavior does not correspond to the differences in density and viscosity between the fuels (see Table 7). However, it has been found that at $25^{\circ} \mathrm{C}$ the lubricity of pure alcohols are similar to each other and worse than hydrocarbon based fuels [37]. The effect of this on the fuel pump might explain the increased variation and lower repeatability of the alcohols compared to gasoline.

\section{Evaluation of Fuel Blend Preparation}

The established improvements (moving average) and corrections (compensation of systematic errors) were applied to the control system of the batch blending system before the fuel blend preparation tests were performed.

Accuracy in Concentration between Blends The measured density of the blends compared to the baseline of gasoline (E0) and ethanol (E100) is shown in Figure 11. The dashed red lines represent the linear interpolation of the range in which the measurement varied for the pure fuel components, hence the uncertainty range of the analysis method. All of the blends are within or close to the expected density 
FIGURE 11 The measured density of the prepared ethanol/ gasoline blends compared to the baseline density.

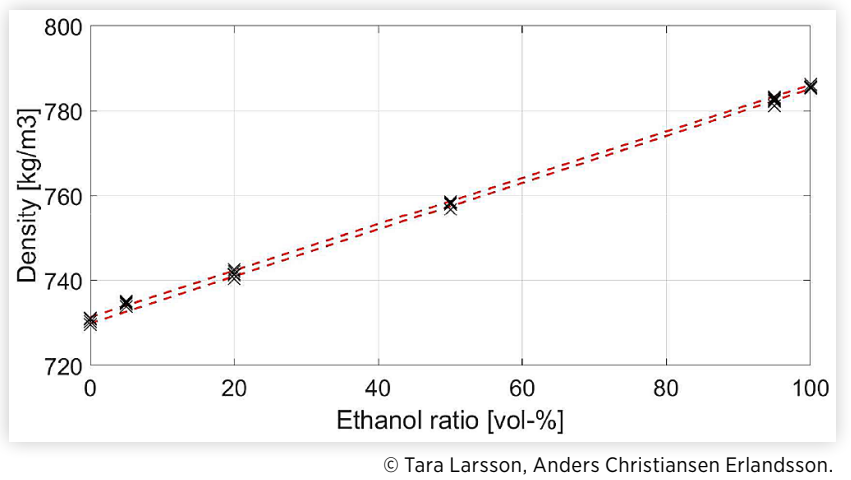

TABLE 8 The mean and highest relative errors of the calculated blend ratio.

\begin{tabular}{|l|l|l|l|}
\hline Fuel blend & $\begin{array}{l}\text { Mean relative } \\
\text { error (\%) }\end{array}$ & $\begin{array}{l}\text { Highest relative } \\
\text { error (\%) }\end{array}$ & $\begin{array}{l}\text { Highest absolute } \\
\text { error (vol-\%) }\end{array}$ \\
\hline E5 & 2.5 & 4.0 & 0.2 \\
\hline E20 & 0.8 & 1.5 & 0.3 \\
\hline E50 & 0.5 & 1.0 & 0.5 \\
\hline E95 & 4.2 & 8.0 & 0.4 \\
\hline \multicolumn{4}{r}{ ( Tara Larsson, Anders Christiansen Erlandsson. } \\
\hline
\end{tabular}

for the respective blend. For E5 the measured density is up to $4 \%$ higher than the expected value. In contrast, the opposite trend is seen for E95 as this blend requires a low demanded gasoline mass. Gasoline was added through inlet 1 and ethanol through inlet 3. Both of the results indicate that for low fuel ratios the corresponding inlet adds more fuel than demanded, as expected due to previous reported limitations of these inlets (see results on 'System limitations').

The calculated ethanol ratios of the blends are close to the demanded value (see Table 8). The relative errors for E5 and E95 were higher than for E20 and E50, but the absolute errors were smaller. The relative error of the prepared blends was less than 4\%, with one exception for E95 showing an 8\% relative error. However, the absolute errors were small: $\leq 0.5$ vol-\% for all tested blends. Therefore, even though the required maximum relative error of $5 \%$ was not fulfilled for all blends, the accuracy of the batch blending system is considered high enough for the intended system implementation.

Variation in Concentration within a Batch To ensure that the prepared blends are homogeneous throughout the mixing vessel, the effect of agitation time was investigated by examining the variation in fuel density between different levels in the mixing vessel. The spread in density of the different levels is presented in Figure 12. The dashed lines represent the linear interpolation of the range in which the measurement varied for the pure fuel components (ethanol and gasoline), hence the uncertainty range of the analysis method.

All blends exhibit a wider spread when no agitation has been implemented. The fuel with the widest spread is E5, whereas for E95 the spread in density is relatively consistent regardless of agitation time. It seems that the highest densities at no agitation are at the top level of the tank, represented by
FIGURE 12 The measured density at different levels in the mixing vessel for the different prepared ethanol/gasoline blends over four different agitation times.

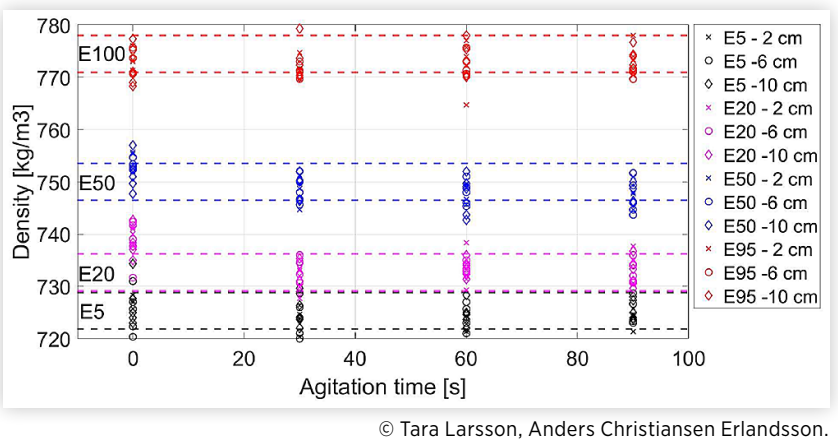

diamond markers in Figure 12. However this trend is not visible for the remaining agitation times investigated.

The results in Figure 12 do not show exactly how long of an agitation time is needed, only that agitation gives a slight improvement to the homogeneity of the prepared blend. The results show that the spread in density for the different levels is decreased compared to when no agitation is implemented. From the presented graph, no clear decrease in the spread of the measured values is seen after 30 seconds. Therefore, it seems that at least 90 seconds of agitation time would be required to achieve homogeneity of the prepared fuel blend. A longer agitation time would probably increase the homogeneity throughout the prepared blend; however, longer agitation times than 90 seconds were not tested in this study. Moreover, an increased agitation time would increase the time needed to prepare the blend. Thus for each system one has to decide which of these factors is the most critical for the specific application.

Previous research has established that the level of separation of alcohol/gasoline fuels depends on the temperature, water concentration, the composition of the gasoline and the ratio of alcohol in the blend $[\underline{38}, \underline{39}]$. Therefore, it is impossible to say if these results would be repeatable with other fuels and at other conditions. Moreover, other researchers has established that a much longer mixing time is needed to ensure fuel homogeneity from $120 \mathrm{~min}$ up to 7 hours $[40,41]$. If those results differs because of the mixing method applied, the difference in fuel composition and water content or the temperature conditions is hard to say but it confirms the need for evaluating the spread in density for this mixing system over a longer agitation time than 90 seconds. The test should also be performed with immiscible mixtures as well, such as methanol and iso-octane [42], and CI fuel mixtures, such as hydrogenated vegetable oil (HVO) and diesel, to ensure adequate agitation for all types of fuel blends.

The retrieved results might also have been affected by the limitations of the applied method to retrieve the samples (a pipette submerged to the different levels), which could have disrupted the blend homogeneity, thus increasing the insecurity of these results. Furthermore, with this method, no randomization could be implemented when retrieving the samples, which also could have affected the outcome of the test. 
TABLE 9 The calculated time to fill the mixing vessel and the delay between sending the control signal and fully open/closed valves for each inlet.

\begin{tabular}{|l|l|l|l|}
\hline Inlet & $\mathbf{1}$ & $\mathbf{2}$ & $\mathbf{3}$ \\
\hline Time to fill $7.3 \mathrm{~kg}[\mathrm{sec}]$ & 85 & 83 & 144 \\
\hline Time to open $[\mathrm{sec}]$ & 4 & 4 & 9 \\
\hline Time to close $[\mathrm{sec}]$ & 6 & 6 & 7 \\
\hline
\end{tabular}

Fuel Blend Preparation Time The fuel blend preparation time depends on which fuel blend is being prepared. Hence the longest possible time is estimated. This time has to meet the requirement set in Table 2 in order not to deplete all the fuel available for the engine in the buffer tank during blend preparation. However, the time requirement in Table 2 is chosen based on this specific application (LD SI) and it might need to be altered depending on the requirements, such as fuel consumption, for each specific system.

The time to fill the mixing vessel and valve delays for each inlet can be seen in Table 9. Since inlet 3 exhibits the lowest flow rate, the maximum time is achieved when most of the fuel is added through this inlet. Hence we assume $0.5 \mathrm{~kg}$ to be filled through inlet 1 and 2 . In the case of iso-butanol, since it has the highest density, $7.1 \mathrm{~kg}$ should be filled through inlet 3 . The resulting maximum blend preparation time (assuming $90 \mathrm{~s}$ of agitation time) is approximately 4.6 minutes. However, this time is dependent on the implemented agitation time and since the necessary agitation time to ensure fuel homogeneity could not be fully established (see results on 'Variation in concentration within a blend'), it cannot be determined if a homogeneous fuel mixture can be prepared in the required 5 minutes or not.

Risk Analysis The results of the risk analysis of the system design can be seen in Appendix 2. None of the investigated fuels had a health factor higher than 1 in the NFPA classification, indicating that none of the fuels is a high threat to human health. Since the involved chemical components in this batch blending system are fuels, they exhibited a combustion factor of 3. Hence the risk of fire in the vicinity of the system is greater than the risks related to human health.

Ensuring fire safety of the batch blending system has been important. There are two ways to prevent a fire: preventing the fuels from forming combustible mixtures or preventing the initiation of a flame. There is ventilation in the engine test cell to prevent the formation of combustible mixtures. However, since this cannot guarantee that such mixtures are not formed in the close vicinity of the mixing vessel, EX-class equipment is used in the system to prevent electrical initiation of fires. Moreover, fire alarms (triggered by increased temperatures) and a spill guard are implemented to prevent the spread of a fire if it did occur.

One additional conclusion from the risk analysis is that a mistake resulting in a large deviation from the expected blend results in a decreased cost compared to manual splash blending. This is because only 10 liters of fuel is prepared at a time. Furthermore, the direct feedback of the added fuel masses and the blend ratios notifies the user immediately of any deviations in the prepared fuel. Therefore, the time for a mistake to occur in the blend preparation for the batch blending system is restricted to the preparation time (5 minutes) and the related cost is only the cost of 10 liters of the prepared fuel (depending on the cost of the fuel components). However, it is important to note that the batch blending system has a high initial cost, which could counteract the cost benefits of the facilitated fuel preparation.

\section{Conclusions}

A fuel batch blending system for continuous production of fuel mixtures for engine research was designed. The system was able to prepare 10 liters of fuel blend with a maximum of three different fuel components.

The fuel batch blending system meets the set requirements and enables the possibility to test various fuel blends in engine testing facilities. It is considered to be fast, accurate and repeatable and ensures safety and functionality throughout fuel blend preparation.

The designed fuel batch blending system is able to:

- Automatically prepare different fuel blends in terms of ratios and fuel components continuously.

- Automatically prepare blends with an absolute error of 0.5 vol- $\%$.

- Facilitate the exchange of broken equipment by using standardized hardware.

- Increased reliability and safety due to the use of adequate materials and EX-class hardware, as well as the implementation of various alarms.

- Facilitate the blend preparation for the user by the implementation of a system program with the capability to monitor the blend preparation process and to $\log$ system data and notification of alarms.

Further development of the batch blending system might include more inlets. These could not only allow for more fuel components, but also lower the linearity and accuracy thresholds of the system, thereby enabling the preparation of even more complex mixtures.

Future work could also include development of the system software to include fuel blend preparation based on the desired fuel properties. This would enable for effective preparation of e.g. primary reference fuels (PRFs) or other reference fuels such as toluene-ethanol reference fuels (TERFs).

\section{References}

1. Hill, J., Nelson, E., Tilman, D., Polasky, S. et al., "Environmental, Economic, and Energetic Costs and Benefits of biodiesel and Ethanol Biofuels," Proceedings of the National Academy of Sciences of the United States of America, National Academy of Sciences 11206-11210, 2006, doi:10.1073/pnas.0604600103. 
2. Yanowitz, J., Christensen, E., and McCormick Robert, L., "Utilization of Renewable Oxygenates as Gasoline Blending Components," 2011.

3. Chang, T.-H., and Su, H.-M., "The Substitutive Effect of Biofuels on Fossil Fuels in the Lower and Higher Crude Oil Price Periods," Energy 35(7):2807-2813, 2010, doi:10.1016/j. energy.2010.03.006.

4. Yusri, I.M., Mamat, R., Najafi, G., Razman, A. et al., "Alcohol Based Automotive Fuels from First Four Alcohol Family in Compression and Spark Ignition ENGINE: A Review on Engine Performance and Exhaust Emissions," Renew. Sustain. Energy Rev. 77:169-181, 2017.

5. Awad, O.I., Mamat, R., Ali, O.M., Sidik, N.A.C. et al., "Alcohol and ether as Alternative Fuels in Spark Ignition Engine: A Review," Renew. Sutsainable Energy Rev. 82:2586$2605,2018$.

6. Wilks, D., “The Impact of Blending Techniques, Feedstock Choice, and Analytical Techniques on Biodiesel Blend Accuracy," in 99th AOCS Annual Meeting \& Expo, Seattle, 2009, 787-789.

7. Pearson, R.J. and Turner, J.W.G., "Renewable Fuels: An Automotive Perspective," in: Sayigh, A., ed., Comprehensive Renewable Energy, Elsevier, 2012, 305-342, ISBN 978-0-08087873-7.

8. Stein, R.A., Anderson, J.E., and Wallington, T.J., “An Overview of the Effects of Ethanol-Gasoline Blends on SI Engine Performance, Fuel Efficiency, and Emissions," SAE Int. J. Engines 6(1):470-487, 2013, doi:https://doi. org/10.4271/2013-01-1635.

9. Anderson, J., Wallington, T., Stein, R., and Studzinski, W., "Issues with T50 and T90 as Match Criteria for EthanolGasoline Blends," SAE Int. J. Fuels Lubr. 7(3), 2014, doi:https://doi.org/10.4271/2014-01-9080.

10. Foong, T.M., Morganti, K.J., Brear, M.J., da Silva, G. et al., "The Octane Numbers of Ethanol Blended with Gasoline and Its Surrogates," Fuel 115:727-739, 2014, doi:10.1016/j. fuel.2013.07.105.

11. Jęczmionek, Ł., Danek, B., Pałuchowska, M., and K, W., "Changes in the Quality of E15-E25 Gasoline during ShortTerm Storage up to Four Months," Energy \& Fuels 31:504513, 2017.

12. Ghotli, R.A., Raman, A.A.A., Ibrahim, S., and Baroutioan, S., "Liquid-Liquid Mixing in Stirred Vessels: A Review," Chem. Eng. Commun. 200(5):595-627, 2013, doi:10.1080/009 $\underline{86445.2012 .717313}$.

13. Cheesewright, R., Belhadj, A., and Clark, C., "Effect of Mechanical Vibrations on Coriolis Mass Flow Meters," J. Dyn. Syst. Meas. Control 125:103-113, 2003, doi:10.1115/1.1539098.

14. Luimes, F., "How to Deal with Vibrations Using Coriolis Mass Flow Meters," https://www.bronkhorst.com/int/blog-1/ how-to-deal-with-vibrations-using-coriolis-mass-flowmeters/, 2019.

15. Morganti, K., Foong, T.M., Brear, M., Da Silva, G. et al., "The Research and Motor octane numbers of Liquefied Petroleum Gas (LPG)," Fuel 108:797-811, 2013, doi:10.1016/j. fuel.2013.01.072.
16. Morganti, K., Foong, T.M., Brear, M., Da Silva, G. et al., "Design and Analysis of a Modified CFR Engine for the Octane Rating of Liquefied Petroleum Gases (LPG)," SAE Int. J. Fuels Lubr. 7(1):283-300, 2014, doi:https://doi. org/10.4271/2014-01-1474.

17. Equilibar, "Differential Pressure Limitations with Mass Flow Controllers," https://www.equilibar.com/application/differentialpressure-limitations-with-mass-flow-controllers/, 2020.

18. Theodore, L., "Batch Reactors," Chemical Reactor Analysis and Applications for the Practicing Engineer, John Wiley \& Sons, 2012, 147-180, doi:10.1002/9781118158630.

19. Theodore, L., "Tubular Flow Reactors," Chemical Reactor Analysis and Applications for the Practicing Engineer, John Wiley \& Sons, 2012, 209-232, doi:https://onlinelibrary.wiley. com/doi/book/10.1002/9781118158630.

20. Theodore, L., "Continuous Stirred Tank Reactors," Chemical Reactor Analysis and Applications for the Practicing Engineer, John Wiley \& Sons, 2012, 181-207, doi:10.1002/9781118158630.

21. Agrawal, S.S., "Fuel Blending Technology and Management," in: Riazi, M., Eser, S., Agrawal, S., and Peña, D., eds., Petroleum Refining and Natural Gas Processing, ASTM International, 2013, 473-497, doi:10.1520/MNL5820131213119.

22. Dimian, A.C., Bildea, C.S., and Kiss, A.A., "Chapter 11 Batch Processes," Computer Aided Chemical Engineering 449-488, 2014, doi:10.1016/B978-0-444-62700-1.00011-5.

23. Sharatt, P. N., "Chemicals Manufacture by Batch Processes," in: Sharatt, P. N. and UMIST, eds., Handbook of Batch Process Design, 1997, 1-23, doi:10.1007/978-94-009-1455-1.

24. Smith, R., "The Nature of Chemical Process Design and Integration," Chemical Process Design and Integration, John Wiley \& Sons Ltd., 2005, 1-15, ISBN 0-471-48680-9.

25. Majozi, T., "Chapter 1 - Introduction to Batch Chemical Processes," Batch Chemical Process Integration, Springer, Dordrecht, 2010, 1-11, doi:10.1007/978-90-481-2588-3.

26. Company, C.R., "Handbook of Chemistry and Physics: A Ready-Reference Book of Chemical and Physical Data," 44th ed., Scholar Select, 1976.

27. Baranowski, C.J., Bahmanpour, A.M., and Kröcher, O., "Catalytic Synthesis of Polyoxymethylene Dimethyl Ethers (OME): A Review," Appl. Catal. B Environ. 217:407-420, 2017, doi:10.1016/j.apcatb.2017.06.007.

28. Härtl, M., Seidenspinner, P., Jacob, E., and Wactmeister, G., "Emission, Oxygenate Screening on a Heavy-Duty Diesel Engine and OME1, Characteristics of Highly Oxygenated Oxymethylene Ether Fuel," Fuel 153:328-335, 2015, doi:10.1016/j.fuel.2015.03.012.

29. Schröder, J., and Görsch, K., "Storage Stability and Material Compatibility of Poly(oxymethylene) Dimethyl Ether Diesel Fuel," Energy \& Fuels 34:450-459, 2020, doi:10.1021/acs. energyfuels.9b03101.

30. Barkalov, A., Titarenko, L., Kolopienczyk, M., Mielcarek, K. et al., "Object Codes Transformation for Moore FSMs," in: Barkalov, A., Titarenko, L., Kolopienczyk, M., Mielcarek, K. et al., eds., Logic Synthesis for FPGA-Based Finite State Machines, Springer International Publishing, 2015, 97-127, doi: $10.1007 / 978-3-319-24202-6$. 
31. Barkalov, A., Titarenko, L., Kolopienczyk, M., Mielcarek, K. et al., "Background of Finite State Machines and Programmable Logic," in: Barkalov, A., Titarenko, L., Kolopienczyk, M., Mielcarek, K. et al., eds., Logic Synthesis for FPGA-Based Finite State Machines, Springer International Publishing, 2015, 1-31, doi:10.1007/978-3-319-24202-6.

32. Johansen, T., and Schramm, J., "Low-Temperature Miscibility of Ethanol-Gasoline-Water Blends in Flex Fuel Applications," Energy Sources Part A(18):1634-1645, 2009, doi:10.1080/15567030903021897.

33. Crawley, F. and Tyler, B., "The HAZOP Study Method," in: Crawley, F. and Tyler, B., eds., HAZOP: Guide to Best Practice, Third Edition, Elsevier, 2015, 10-12, doi:10.1016/ B978-0-323-39460-4.00003-7.

34. Pasman, H., "Loss Prevention History and Developed Methods and Tools," in: Pasman, H., ed., Risk Analysis and Control for Industrial Processes - Gas, Oil and Chemicals, Butterworth-Heinemann, 2015, 79-184, doi:10.1016/B978-012-800057-1.00003-1.

35. Canada, G. of, "Volume Correction Factors-Gasoline and Gasoline Ethanol Blends," https://www.ic.gc.ca/eic/site/mcmc.nsf/eng/lm00129.html.

36. DDB, "Liquid Density Calculation by DIPPR105 Equation," http://ddbonline.ddbst.de/DIPPR105DensityCalculation/ DIPPR105CalculationCGI.exe?component=Ethanol, 2020.

37. Lapuerta, M., García-Contreras, R., Campos-Fernández, J., and Pilar Dorado, M., "Stability, Lubricity, Viscosity, and Cold-Flow Properties of Alcohol-Diesel Blends," Energy \& Fuels 24:4497-4502, 2010, doi:10.1021/ef100498u.

38. Osten, D.W., and Sell, N.J., "Methanol-Gasoline Blends: Blending Agents to Prevent Phase Separation," Fuel 62:268270, 1983, doi:10.1016/0016-2361(83)90079-0.

39. Karaosmanoğlu, F., Asli, I., and Aksoy, H.A., "Effects of a New Blending Agent on Ethanol-Gasoline Fuels," Energy \& Fuels 10(3):816-820, 1996, doi:10.1021/ef950131z.

40. Zyada, A., and Samimi-Abianeh, O., "Ethanol Kinetic Model Development and Validation at Wide Ranges of Mixture Temperatures, Pressures and Equivalence Ratios," Energy \& Fuels 33:7791-7804, 2019, doi:10.1021/acs.energyfuels.9b01035.

41. Walyuyo, B., Wardana, I.N.G., Yuliati, L., Sosongko, M.N. et al., "The Role of Ethanol as Cosolvent on the Separated Gasoline Methanol Blend," IOP Conf. Ser. Mater. Sci. Eng. 674, 2019, doi:10.1088/1757-899X/674/1/012005.

42. SigmaAldrich, "Solvent Miscibility Table," https://www. sigmaaldrich.com/chemistry/solvents/solvent-miscibilitytable.html, 2020.

43. Karlsson, H.T., "Riskanalys," Processriskanalys, Department of Chemical Engineering, Lund University of Technology, 97-130, 2012.

44. (AIChE), A.I.O.C.E., "Dow's Fire and Explosion Index Hazard Classification Guide,” Wiley, ISBN 978-0-816-90623-9, 1994.

\section{Acknowledgments}

This work is conducted within the project "Future alternative transportation fuels" and the authors would like to thank the contributing partners: the Swedish Energy Agency, Chevron, Lantmännen, Perstorp AB, Preem, Scania CV AB, St1, Saybolt Sweden, Stena Line, Volvo AB and Volvo Cars.

The authors would like to thank the laboratory personnel at KTH Engine laboratory for all the help in designing, building and connecting the fuel batch blending system. We would also like to express our gratitude to Prof. Lars Pettersson at Process Technology at KTH for granting us access to equipment and the laboratory for the analysis of the blends.

\section{Definitions/Abbreviations}

\section{CI - Compression Ignition}

cRIO - Compact Reconfigurable Input/Output

CSTR - Continuously Stirred Tank Reactor

DME - Dimethyl ether

ED95 - Fuel for heavy-duty application containing 95\% ethanol and 5\% Diesel

EX-class - Explosion proof classification

EXX - Fuel blend containing XX volume percentage of ethanol

FAME - Fatty acid methyl ester

FSM - Finite State Machine

GUI - Graphical User Interface

HazOp - Hazards and Operability studies

HD - Heavy-duty

HVO - Hydrogenated vegetable oil

LD - Light-duty

MFC - Mass flow controller

NFPA - U.S National Fire Protection Association

NI - National Instruments

OME - Oxymethylene dimethyl ethers

PRF - Primary reference fuels

PTFE - Polytetrafluoroethylene

SI - Spark Ignited

TERF - Toluene-ethanol reference fuels

\section{Contact Information}

Tara Larsson

taral@kth.se 


\section{Appendix 1}

The table describes the hardware used for the fuel blending system in detail. The numbers visible under "Numbered items" are referencing to the numbers in Figure 1.

TABLE A1 Detailed description of hardware used for the fuel blending system.

\begin{tabular}{|c|c|c|c|}
\hline Numbered item: & Description: & Model/material: & Measurement/range: \\
\hline 1. & Inlet pipe for fuel 1 & Stainless steel pipe with quick coupling & $\varnothing 10 \mathrm{~mm}$ \\
\hline 2. & Inlet pipe for fuel 2 & Stainless steel pipe with quick coupling & $\varnothing 10 \mathrm{~mm}$ \\
\hline 4. & $\begin{array}{l}\text { Temperature sensors fuel } \\
\text { (one in each inlet) }\end{array}$ & Thermocouple type K, ø $1.5 \mathrm{~mm}$ & $-200-1260^{\circ} \mathrm{C}$ \\
\hline 5. & Inlet valve fuel 1 & Solenoid valve, ATEX-class II & Digital on/off $24 \mathrm{~V}$ \\
\hline 8. & Inlet pump for inlet fuel 3 & Bosch 044 fuel pump & $0-5$ bar $(200 \mathrm{I} / \mathrm{h}$ at 5 bar $) 12 \mathrm{~V}$ \\
\hline 9. & Motor for the fuel stirrer & $\begin{array}{l}\text { Pneumatic motor Buddeberg PLR28 Stainless } \\
\text { steel ATEX-class II }\end{array}$ & $\max 6$ bar max $400 \mathrm{rpm} 10.4 \mathrm{Nm}$ \\
\hline 10. & Mixing vessel & Cylindrical container in stainless steel & $ø 250$, h $350(\mathrm{~mm})$ \\
\hline 15. & Fuel pressure regulator & Bosch MiniA & 2.2-3.5 bar $15-220 \mathrm{I} / \mathrm{h}$ reflow \\
\hline 16. & Return line & PTFE hose & \\
\hline 17. & Outlet & Stainless steel pipe with quick coupling & $\varnothing 10 \mathrm{~mm}$ \\
\hline 18. & Pressure sensor inlet & GE Unik 5000 Gauge sensor ATEX-class II & 0-10 bar \\
\hline 19. & Temperature sensor container & Thermocouple type $\mathrm{K}$ & $-200-1260^{\circ} \mathrm{C}$ \\
\hline 20. & Pressure sensor outlet & GE Unik 5000 Gauge sensor ATEX-class II & 0-10 bar \\
\hline 21. & Level indicator & On/off level switch & Digital $5 \mathrm{~V}$ \\
\hline 22. & Buffer tank & AVL Fuel scale & 2 liters (1850 g) \\
\hline
\end{tabular}

\section{Appendix 2}

Full Hazard and Operability Studies (HazOp) risk analysis with consequences and safeguards. The analysis was made following guidelines from $[\underline{34}, \underline{43}]$. The NFPA classification for some fuels can be seen in Table A2. These factors were taken into consideration when determining the consequences in the HazOp-analysis.

TABLE A2.1 NFPA classification for some fuels [43], original from [44].

\begin{tabular}{|l|l|l|l|}
\hline Fuel & Combustion factor $\left(\mathbf{N}_{\mathbf{f}}\right)$ & Reactivity factor $\left(\mathbf{N}_{\mathbf{f}}\right)$ & Health factor $\left(\mathbf{N}_{\mathbf{h}}\right)$ \\
\hline nButanol & 3 & 0 & 1 \\
\hline Diesel & 2 & 0 & 0 \\
\hline Ethanol & 3 & 0 & 0 \\
\hline Gasoline & 3 & 0 & 1 \\
\hline Methanol & 3 & 0 & 1 \\
\hline
\end{tabular}


The HazOp-analysis was performed with the guidewords listed below, and also included causes and consequences.

1. More

2. Less

3. None

4. Reverse

5. As well as

6. Part of

7. Other than

The results from the full analysis can be seen in Table A2.2.

TABLE A2.2 HazOp analysis for the fuel blending system including consequences and safeguards.

\begin{tabular}{|c|c|c|c|c|c|}
\hline \multicolumn{6}{|l|}{ Inlet flow } \\
\hline Guide word & Cause & Consequences & Probability & Severity & Safeguards \\
\hline More & Increased pump pressures & $\begin{array}{l}\text { Increased flow to blend } \\
\text { container }\end{array}$ & Medium & Low & Container safety margin \\
\hline Less & Decreased pump pressures & $\begin{array}{l}\text { Decreased flow to blend } \\
\text { container }\end{array}$ & Medium & Low & No consequence \\
\hline Less & Leakage & $\begin{array}{l}\text { Fuel spill - hazardous } \\
\text { fumes and/or fire }\end{array}$ & Low & $\begin{array}{l}\text { Medium to } \\
\text { high }\end{array}$ & $\begin{array}{l}\text { Spill guard Thermocouples } \\
\text { to detect fire }\end{array}$ \\
\hline None & $\begin{array}{l}\text { Fuel is depleted Malfunctioning } \\
\text { valves or pumps }\end{array}$ & $\begin{array}{l}\text { No flow to blend } \\
\text { container }\end{array}$ & Low & Medium & $\begin{array}{l}\text { Fuel mass observed in GUI } \\
\text { Pressure sensor in inlet }\end{array}$ \\
\hline Reverse & \multicolumn{5}{|l|}{ Not possible } \\
\hline As well as & Deviating concentration & $\begin{array}{l}\text { Fuel blend is not the } \\
\text { expected one }\end{array}$ & Very unlikely & Medium & Offsite fuel tests \\
\hline Part of & $\begin{array}{l}\text { Fuel contamination in storage } \\
\text { or from pipes }\end{array}$ & $\begin{array}{l}\text { Small deviation in fuel } \\
\text { blend }\end{array}$ & Medium & Low & Offsite fuel tests \\
\hline Other than & $\begin{array}{l}\text { Another fuel is connected to } \\
\text { the inlet }\end{array}$ & $\begin{array}{l}\text { The fuel blend is not the } \\
\text { expected one }\end{array}$ & Very low & Medium & $\begin{array}{l}\text { Start-up protocol User } \\
\text { responsibility }\end{array}$ \\
\hline \multicolumn{6}{|l|}{ Outlet flow } \\
\hline Guide word & Cause & Consequences & Probability & Severity & Safeguards \\
\hline More & Increased pump pressure & $\begin{array}{l}\text { Increased flow out of } \\
\text { blend container }\end{array}$ & Medium & Low & No severe consequences \\
\hline Less & Decreased pump pressure & $\begin{array}{l}\text { Decreased flow out of } \\
\text { blend container }\end{array}$ & Medium & Low & No severe consequences \\
\hline None & $\begin{array}{l}\text { No fuel in blend container } \\
\text { Malfunctioning pump or valve }\end{array}$ & $\begin{array}{l}\text { No fuel to buffer tank, } \\
\text { engine }\end{array}$ & Low & Medium & $\begin{array}{l}\text { Buffer tank Pressure } \\
\text { sensors in outlet }\end{array}$ \\
\hline Reverse & \multicolumn{5}{|c|}{ Not possible } \\
\hline As well as & \multicolumn{5}{|c|}{ In that case from inlet errors (see inlet flow section) } \\
\hline Part of & $\begin{array}{l}\text { Contamination in outlet pipe } \\
\text { or fuel blend container }\end{array}$ & $\begin{array}{l}\text { The fuel blend is not the } \\
\text { expected one }\end{array}$ & Very low & Low & $\begin{array}{l}\text { Run engine before logging } \\
\text { test data to "clean out" } \\
\text { pipes Offsite fuel tests }\end{array}$ \\
\hline Other than & \multicolumn{5}{|c|}{ In that case from inlet errors (see inlet flow section) } \\
\hline \multicolumn{6}{|c|}{ Container level } \\
\hline Guide word & Cause & Consequences & Probability & Severity & Safeguards \\
\hline More & $\begin{array}{l}\text { Fuel inlets are not closed } \\
\text { properly - malfunctioning } \\
\text { valves }\end{array}$ & $\begin{array}{l}\text { Overflow and fuel } \\
\text { leakage from container }\end{array}$ & Low & $\begin{array}{l}\text { Medium to } \\
\text { high }\end{array}$ & $\begin{array}{l}\text { Spill plate beneath fuel } \\
\text { container Vessel safety } \\
\text { margin Alarms in software }\end{array}$ \\
\hline
\end{tabular}


TABLE A2.2 (Continued). HazOp analysis for the fuel blending system including consequences and safeguards.

\begin{tabular}{|c|c|c|c|c|c|}
\hline \multicolumn{6}{|l|}{ Inlet flow } \\
\hline Guide word & Cause & Consequences & Probability & Severity & Safeguards \\
\hline Less & $\begin{array}{l}\text { Fuel outlet is not closed } \\
\text { properly - malfunctioning } \\
\text { valves }\end{array}$ & $\begin{array}{l}\text { All fuel in container is } \\
\text { depleted }\end{array}$ & Low & Low & $\begin{array}{l}\text { Monitoring container levels } \\
\text { and valves in GUI Refill fuel } \\
\text { and/or check outlet valves }\end{array}$ \\
\hline None & No fuel in the container & $\begin{array}{l}\text { All fuel in container has } \\
\text { been depleted and no } \\
\text { refill of fuel }\end{array}$ & Very low & Low & $\begin{array}{l}\text { Stop system and check } \\
\text { outlet valves }\end{array}$ \\
\hline As well as & $\begin{array}{l}\text { The GUI level indication is } \\
\text { wrong Scale signal is not } \\
\text { correct }\end{array}$ & $\begin{array}{l}\text { Could lead to overflow } \\
\text { or fuel depletion }\end{array}$ & $\begin{array}{l}\text { Low to } \\
\text { medium }\end{array}$ & Low & $\begin{array}{l}\text { Container safety margin } \\
\text { Alarms in software } \\
\text { Monitoring container levels } \\
\text { and valves in GUI Refill fuel } \\
\text { and/or check outlet valves }\end{array}$ \\
\hline \multicolumn{6}{|c|}{ Mixing (motor + agitator) } \\
\hline Less & $\begin{array}{l}\text { Decreased air pressure to } \\
\text { pneumatic motor }\end{array}$ & Slower mixing & Low & Low & $\begin{array}{l}\text { No severe consequences } \\
\text { (mixing should still } \\
\text { be adequate) }\end{array}$ \\
\hline None & $\begin{array}{l}\text { The pneumatic motor is } \\
\text { malfunctioning No pressurized } \\
\text { air to the motor }\end{array}$ & Inhomogeneity of fuel & Low & $\begin{array}{l}\text { Low to } \\
\text { medium }\end{array}$ & $\begin{array}{l}\text { User checks that the motor } \\
\text { is working at system start- } \\
\text { up GUI monitoring of signal } \\
\text { to air valve }\end{array}$ \\
\hline Reverse & \multicolumn{5}{|c|}{ Not possible the motor can only rotate in one direction - otherwise no effect on the mixing } \\
\hline \multicolumn{6}{|c|}{ Temperature (above container) } \\
\hline Guide word & Cause & Consequences & Probability & Severity & Safeguards \\
\hline More & $\begin{array}{l}\text { Fire of fuel gases above or } \\
\text { inside container }\end{array}$ & $\begin{array}{l}\text { Destroyed equipment } \\
\text { Personal injuries }\end{array}$ & Low & High & $\begin{array}{l}\text { Thermocouples + alarms to } \\
\text { monitor Forced ventilation } \\
\text { to avoid flammable gas }\end{array}$ \\
\hline Less & \multicolumn{5}{|c|}{ The lowest possible temperature is ambient. } \\
\hline \multicolumn{6}{|c|}{ Liquid level spill plate } \\
\hline Guide word & Cause & Consequences & Probability & Severity & Safeguards \\
\hline More & $\begin{array}{l}\text { Fuel leakages somewhere in } \\
\text { the system }\end{array}$ & $\begin{array}{l}\text { Could lead to the } \\
\text { formation of toxic or } \\
\text { flammable gases }\end{array}$ & Low & $\begin{array}{l}\text { Medium to } \\
\text { high }\end{array}$ & $\begin{array}{l}\text { Liquid level guard on spill } \\
\text { plate connected to alarms }\end{array}$ \\
\hline Less & \multicolumn{5}{|c|}{ Not possible as normal level is none } \\
\hline None & \multicolumn{5}{|l|}{ Normal operation } \\
\hline
\end{tabular}

(c) 2020 Tara Larsson, Anders Christiansen Erlandsson. Published by SAE International. This Open Access article is published under the terms of the Creative Commons Attribution License (http://creativecommons.org/licenses/by/4.0/), which permits distribution, and reproduction in any medium, provided that the original author(s) and the source are credited.

Positions and opinions advanced in this work are those of the author(s) and not necessarily those of SAE International. Responsibility for the content of the work lies solely with the author(s). 